\title{
Teorias do reconhecimento e sua validade heurística para a análise da cidadania e movimentos sociais no Brasil - o caso do movimento negro
}

Angela Randolpho Paiva'

\section{Resumo}

O presente artigo pretende trazer três teorias, sobre cidadania, sobre movimentos sociais e sobre as teorias do reconhecimento de Nancy Fraser e Axel Honneth, teorias produzidas no "norte", no sentido de ver sua validade heurística para a compreensão das questões contemporâneas do Brasil. Pretende-se mostrar que trazem grande aporte para a análise da esfera pública brasileira desde a redemocratização do país. Partindo de uma sociologia histórica, vai ser enfatizada a transformação que vem acontecendo nos acordos normativos da esfera pública, no que concerne tanto à emergência de movimentos sociais quanto ao questionamento das desigualdades persistentes no Brasil em torno da questão racial. Vai ser defendido que o ideário de direitos é instrumento poderoso para a conquista de nova cidadania, e que a teoria do reconhecimento representa importante chave analítica para a compreensão dos novos movimentos sociais.

Palavras-chave: Cidadania. Desigualdade. Formas de Reconhecimento. Movimento Negro.

\section{Introdução}

Muito se comenta acerca da validade heurística de conceitos centrais da filosofia política e sociologia desenvolvidos pelos países centrais, "do norte", para a análise das questóes sociais dos países periféricos, "do sul". Afinal, eles podem ser aplicados à análise das questóes contemporâneas do cenário brasileiro? Eles resistem às diferenças nos padrōes históricos de cultura

I Professora associada de sociologia no Programa de Pós-Graduação em Ciências Sociais (PPG-CIS) do Departamento de Ciências Sociais da Pontifícia Universidade Católica do Rio de Janeiro (PUC-Rio). Diretora da Coordenação Central de Cooperação Internacioanl (CCCI) da PUC-Rio. E-mail: apaiva@puc-rio.br

$(\infty)$ EY
Direito autoral e licença de uso: Este artigo está licenciado sob uma Licença Creative Commons. Com essa licença você pode compartilhar, adaptar, para qualquer fim, desde que atribua a autoria da obra, forneça um link para a licença, e indicar se foram feitas alterações. 
política das sociedades periféricas? No caso do Brasil especificamente, como falar de autonomia do sujeito, defendida por Hannah Arendt (1993) e Habermas (1984) como necessária para a participação na esfera pública, em um país que apresenta padróes históricos abissais de desigualdade social? Como falar da universalização da fruição dos direitos humanos no Brasil, conhecido por sua cidadania para alguns? Mais, ainda, como falar de padróes normativos que norteiam acordos societários com base no reconhecimento do indivíduo de igual valor, como analisou Charles Taylor (1994), em uma sociedade que construiu um acordo social ambivalente, em uma complexa convivência de elementos tradicionais com modernos, e com a divisão profunda de seus grupos sociais?

Estas são algumas das perguntas que vão guiar a presente análise. Pretende-se responder afirmativamente a todas elas, pois se defenderá que conceitos centrais sobre construção social da cidadania, sobre a teoria do reconhecimento e a dos movimentos sociais têm grande validade heurística para a análise das questôes contemporâneas do Brasil, tomadas a partir de uma perspectiva crítica. Da cidadania, cabe registrar não apenas as bases sociais e políticas para sua realizaçáo efetiva mas também as condiçóes materiais para a universalizaçáo dos diversos tipos de direitos no marco legal, em um acordo normativo que combine a igualdade com o direito à diferença. Da teoria do reconhecimento, é importante trazer o núcleo central do reconhecimento social que deve orientar os acordos normativos da relaçáo sociopolítica brasileira para decifrar quando não está presente o devido reconhecimento a grupos sociais que compóem a sociedade mais ampla, e em que instâncias a estes é negado. Dos movimentos sociais, a literatura sobre o ator social, repertórios de lutas, a formação de identidades coletivas e os novos frames que se apresentam na esfera pública traz grande aporte para a análise dos conflitos contemporâneos do país. Assim, os três eixos centrais que vão ser desenvolvidos estão interligados, pois a análise crítica do acordo social contemporâneo brasileiro deve passar não apenas pela análise da fruição incompleta dos direitos na formação social excludente brasileira, como também do não reconhecimento de vários grupos que são excluídos ou discriminados. E vai ser mostrada como a teoria do reconhecimento construída por Honneth e Fraser pode assumir papel central quando relacionada à discussão da construção social da cidadania para 
se abordarem as questóes contemporâneas em uma perspectiva da teoria crítica. Como pano de fundo da análise que segue, será trazido um movimento social que se consolidou no processo de redemocratização do país, momento em que os vários movimentos negros existentes se aglutinaram no Movimento Negro Unificado (MNU).

Lançando mão da sociologia histórica para a compreensão da complexa relação entre os ideais republicanos de igualdade e liberdade da República e o momento de redemocratização do país, momento em que todos os déficits das promessas republicanas são trazidos à tona na esfera pública, pode-se perceber a latência dos vários conflitos subjacentes à construção da nossa desigualdade estrutural republicana, e como estes podem surgir com a produção social da ação coletiva. Com a redemocratização, movimentos sociais dos mais diversos se uniram em novas concertaçóes coletivas para cobrarem seus direitos não reconhecidos. São formas de luta pela fruição de direitos negados, cobrados no seu marco substantivo. Rejeitaram-se, assim, as promessas apenas no plano formal das várias ediçóes anteriores da constituição brasileira, com a denúncia do não reconhecimento das promessas prescritas anteriormente, e que a Carta de 1988 possibilitava novas dimensóes para a fruição dos diversos tipos de direitos. Foi o que aconteceu com os vários movimentos negros de várias orientaçóes que se unificam em 1978, cujo consenso se traduziu em duas bandeiras principais: a denúncia da falácia da democracia racial brasileira e a reivindicação da fruição efetiva de direitos, em especial o acesso à justiça, à educação e à saúde. Vários coletivos negros participaram ativamente da Assembleia Constituinte (1987-1988) e pautaram essas demandas no momento de preparação da nova Carta.

\section{A redemocratização e os movimentos sociais}

As promessas da nova Constituição aprovada em 1988 traduziam princípios que requeriam novos acordos da ordem social para que se tornassem leis efetivas no que anteriormente havia sido formalmente acordado. Foram, portanto, lançadas as bases para a fruição de antigos direitos não reconhecidos, como o acesso a terra e/ou à moradia, na chave de sua funçáo social, novos direitos construídos por movimentos sociais contemporâneos desde a década de 1960 - como os direitos das mulheres, ambiental, LGBT e de pessoas com deficiência -, além 
das novas reconfiguraçóes de movimentos latentes, como o dos negros e dos povos indígenas. Era o pedido da fruição náo apenas dos direitos civis, políticos e sociais, mas também dos direitos coletivos dos povos indígenas e quilombolas. Para a teoria social brasileira, estas novas formas de reivindicação trouxeram a necessidade de outras interpretações sobre as questóes que estavam sendo pautadas no país. O pano de fundo era a desigualdade exposta por indicadores sociais que não eram unicamente explicados na chave das classes sociais (GUIMARÃES, 2002).

Os movimentos sociais tornaram-se um fenômeno global a partir da década de 1960, quando diversos grupos começaram a denunciar o marco excludente da promessa de igualdade da modernidade em seus países. Assim, novas teorias se fizeram necessárias para interpretar as mudanças sociais ocorridas desde então, quando as "mudanças estruturais na esfera pública" foram demandadas por movimentos que chegaram com novas identidades coletivas, novos marcos interpretativos (frames), e com o protagonismo renovado da sociedade civil organizada. Foi um fenômeno global de reação às promessas não cumpridas do modelo das democracias modernas de que todos são "livres e iguais perante a lei". Foi, portanto, sendo formulada a teoria dos movimentos sociais, cujo objetivo central era compreender as novas relaçóes entre agência e estrutura que estavam sendo colocadas: com construçóes de novas subjetividades que não eram contempladas na chave do trabalho organizado; com a formação de ação coletiva à margem das redes clássicas de sindicatos do mundo do trabalho; e com repertórios de atuação na esfera pública que vinham dessa nova agência a demandar novos direitos ou direitos náo realizados; e, mais recentemente, com a perda de direitos do projeto neoliberal globalizante. Todas estas questóes estão presentes no cenário brasileiro.

No nível teórico, surgiram estudos da ação coletiva de conflitos, que pediam novas análises para a compreensão das dinâmicas sociais, destacando-se aqui o surgimento da sociologia da ação e o da mobilização de recursos. A primeira teve como porta-voz pioneiro Alain Touraine (2009), que analisou e conceituou o ator social desde os movimentos estudantis e feministas dos anos 1960, ou seja, movimentos construídos em novas ações coletivas para a denúncia da igualdade incompleta republicana francesa, cujo marco principal ressaltou a subjetivação necessária para o nascimento 
do sujeito, o que ele chamaria de individuação anos mais tarde. Também Melucci (2001) trouxe chaves teóricas fundamentais para a compreensão dos desafios postos por essa nova agência, no que vai chamar de "produção social da identidade coletiva”. Para tal análise, alerta Melucci, é preciso atentar tanto para o nível individual de subjetivação quanto para o nível social na sua interação com o ambiente, nas redes de identidade coletiva em torno de novas questôes.

A segunda chave debruçou-se sobre as dinâmicas do protesto para a análise do conflito e da identidade coletiva, no que se refere aos repertórios inovadores de ação coletiva (um deles, a ação direta não violenta); aos quadros interpretativos (frames) construídos pelos atores que se formavam para traduzirem novas representaçóes e valores, fundamentais na proposta de mudança social; e às açóes coletivas que eram constituídas para a participação na esfera pública. Nessa segunda chave, foi dada especial atenção às oportunidades políticas e à mobilização de recursos para a análise do surgimento de novos movimentos sociais. Três autores sobressaem para a análise dos novos ciclos de protesto que ocorriam nos Estados Unidos na década de 1960: Charles Tilly (1978) ressaltou a importância tanto da construção da identidade coletiva como "categoria", quanto para a construção de redes para a consolidação da mobilização, que ele descreveu como catnet, abreviação de category e network; Doug McAdam (1982) apontou para a importância do engajamento de indivíduos em movimentos sociais para a construção de frames, ao que chamou de "liberação cognitiva" dos participantes em movimentos; e Sidney Tarrow (1998) destrinchou as principais categorias presentes nos movimentos sociais. Todos ressaltam a importância do confronto político para a formação de movimentos contemporâneos. ${ }^{2}$

Ambas as correntes trazem importantes categorias para a análise dos movimentos sociais brasileiros que ressurgem no final da década de 1970 e início de 1980, quando o regime militar estava nos seus estertores e novas oportunidades políticas eram encontradas pelos atores que se organizavam. Destapava-se, assim, a “panela de pressão” dos vários movimentos reprimidos

2 Estão sendo trazidos três dos principais teóricos sobre os ciclos de protesto e mobilizações coletivas. O objeto principal de suas análises era o Movimento dos Direitos Civis americano, que ocorreu a partir do final da década de 1950. 
desde 1964, e que culmina com o reconhecimento da legitimidade de suas demandas na Carta de 1988. A questão dos direitos humanos entrou com força nas discussôes da Constituinte e se concretizou em uma Constituição que deu voz a vários grupos não reconhecidos até então. Para a teoria social brasileira, portanto, os déficits reconhecidos no que concerne à fruição dos vários direitos se tornaram foco de muita análise para a compreensão da complexidade e dos desafios postos depois de décadas de repressão tanto política quanto social. Também houve a necessidade de novas interpretaçôes teóricas acerca dos movimentos sociais com várias orientaçóes que se consolidavam na esfera pública redemocratizada. Assim, questóes como cidadania e direitos humanos, por exemplo, foram analisadas em novas chaves como a função social da terra e da moradia, direitos não reconhecidos aos povos indígenas, e a desigualdade racial estrutural, dentre outras. Assim, novos conceitos ganharam força nesse momento para interpretar as desigualdades persistentes da formação social brasileira, de movimentos que buscavam a efetiva realização da justiça social.

No nível analítico, o que se viu desde a década de 1960 foi o surgimento de vários processos de mudança da ação social no mundo ocidental, quando grupos de ação coletiva denunciaram não estarem contemplados no ideário de direitos humanos de seus países. Foi assim com o feminismo, com o movimentos dos direitos civis, com os povos nativos; desde então, foram surgindo novas identidades coletivas, socialmente construídas (CALHOUN, 1994) para a denúncia das desigualdades duráveis (TILLY, 1999) em torno de classe, gênero, raça e regiáo das sociedades capitalistas ocidentais. No caso brasileiro, os movimentos sociais tiveram de esperar até o final da década de 1970, quando o regime militar dava sinais de esgotamento, para organizarem suas demandas, que já vinham sendo construídas em espaços da sociedade civil, como foi o caso da ala progressista da Igreja Católica, que possibilitou a formação de "espaços públicos" nas diversas pastorais que foram formadas como espaço público alternativo para uma esfera pública controlada pelo regime militar. ${ }^{3}$

3 Cabe ressaltar a importância da Igreja Católica progressista que desde o final da década de 1950 denunciava a desigualdade brasileira com a formação da Ação Católica (PAIVA, 20I3), que veio a ser o embrião da Teologia da Libertação. Foi a origem das Comunidades Eclesiais de Base (CEBs) e das diversas pastorais 
A década de 1980 traduziu, portanto, a reorganização de grupos que passaram a denunciar as desigualdades estruturais do acordo societário do país. Como bem ressaltou Eunice Durham (1984), naquele momento era preciso encontrar novas chaves analíticas para compreender a construção da cidadania reivindicada por movimentos que traziam "novas necessidades", como analisa a autora. Assim, tanto global como localmente, os movimentos sociais obrigaram a que se pensasse em novas formulaçóes para a teoria social contemporânea, quando foi preciso se debruçar sobre a formação do ator social, sobre a construção da identidade coletiva, dos repertórios de ação, das estratégias para atuação na esfera pública, das redes construídas, além da tarefa urgente de interpretação dos novos frames que eram trazidos para a esfera pública desses "espaços contra públicos”, como bem registra Fraser $(1990,1995)$, a construção de ação concertada nos grupos subalternos, que podem chegar à esfera pública reivindicando mudanças nos padrôes culturais e socioeconômicos. ${ }^{4} \mathrm{E}$ esses grupos vão aportar subsídios para a teoria crítica, tanto na dimensão cultural quanto econômica, no que se refere a novas possibilidades de movimentos emancipatórios. Dessa forma, a chave de direitos equacionada com as diversas formas de desigualdade e subalternidade perpassa a discussão feita a seguir.

\section{Que direitos?}

Para que a análise da construção social da cidadania possa estar na chave da teoria crítica proposta aqui, é preciso sempre equacioná-la com a fruição efetiva dos diversos tipos de direitos, relacioná-la aos padróes de desigualdade existentes, além de verificar as possibilidades de novas mobilizações. A análise clássica de Marshall (1967) sobre o desenvolvimento da cidadania na Inglaterra mostra como os direitos civis propiciaram a

(operária, da terra, do negro, dentre outras) da década de 1970, espaços fundamentais para o processo de redemocratização.

4 Está se utilizando aqui o conceito habermasiano de esfera pública, vale dizer, a esfera construida a partir do momento em que questões consideradas antes da esfera privada são trazidas para a esfera pública. E se no século XVIII era a esfera pública burguesa da concepção de Marx, no século XX já havia acontecido o alargamento da sociedade civil europeia com a inclusão da classe trabalhadora no estado de bem-estar social, quando então Habermas (1984) fala de "esfera social". Como pressuposto, está a igualdade minima como condição para a participação na esfera pública, a mesma condição pensada por Hannah Arendt em $A$ Condição Humana. 
luta pelos direitos políticos e como estes foram importantes para a conquista dos direitos sociais. Sua análise, no entanto, foi feita em um momento de muito otimismo e muito crescimento econômico no Pós-Guerra, quando as sociedades de capitalismo avançado puderam pensar nos seus modelos de welfare state para que fosse atingido o "status" da cidadania, preconizado por Marshall. Assim, chegaram os direitos sociais universalizados na educação e saúde para essas sociedades, direitos que iriam mitigar de certa forma as desigualdades estruturais do sistema capitalista (BENDIX, 1969). Mas tais possibilidades de integração social fazem parte de uma história que pode ser contada até a década de 1980, quando a guinada neoliberal e novas tecnologias que surgiram no mundo do trabalho representaram efetiva perda e “desfiliação" (CASTEL, 1998) sistemática do trabalho organizado até então.

No caso brasileiro, houve também grande crescimento econômico nesse período, mas realizado em uma outra chave, uma vez que estava mantida a ordem paradoxal de um desenvolvimento pelo alto, com os direitos sociais sendo "doados" pelo Estado conservador, e depois autoritário, com 21 anos de ditadura militar. Mas o período aqui enfatizado, a partir da década de 1980, com grande mobilização de novas formas de concertação social da sociedade civil, trouxe a demanda simultânea por direitos civis, políticos, sociais e culturais. Foi assim no campo e na cidade, quando a ideia de direitos passou a nortear formas de resistência ou de confronto na esfera pública (GOHN, 2010). Assim, pode-se comentar sobre em uma "cidadania insurgente", como bem definiu James Holston (2013), quando analisa as novas formas de organização coletiva das regiốes periféricas de São Paulo que surgiram desde a década de 1970.

O cenário foi de otimismo na década de 1990, com formas renovadas de participação da sociedade civil, com partidos reorganizados e os direitos assumindo a preeminência como os "reguladores das práticas sociais", como definiu Vera Telles (1994), cujas novas possibilidades de realização estavam postas com a redemocratização. Foi o momento de se rever os "nexos constitutivos" entre as dimensôes da cultura e da política que os movimentos sociais reivindicavam para a transformaçáo cultural efetiva que pudesse trazer a realização da cultura democrática, como ressaltou Evelina Dagnino (1994). Eram os remédios para o arranjo excludente da nossa ordem social. A mesma autora vai falar na década seguinte em "confluência 
perversa” no cenário brasileiro para descrever a perda de direitos com os novos arranjos neoliberais, concomitante com as demandas da ação coletiva organizada a pedir novos direitos.

Tal confluência perversa foi ainda mais acentuada na década de 2010, no momento em que o Estado ficou refém de velhas práticas políticas de clientelismo e corrupção, juntamente com a incapacidade de realização das demandas dos movimentos sociais por reconhecimento e redistribuição. Pode-se afirmar que há mesmo um descompasso entre as demandas da sociedade civil organizada - cada vez mais consciente de seus direitos a partir da redemocratização - e a política, cujos partidos políticos, que persistem em velhas práticas de clientelismo e corrupção, sofrem com a perda de confiança na representação partidária. Mas cabe lembrar que a ideia de direitos é poderosa e sempre móvel de ação para novos confrontos que podem surgir na esfera pública democrática brasileira. É o que se tem presenciado desde a década de 1980 em várias formas de organização coletiva e as demandas tanto por reconhecimento quanto por redistribuição vêm sendo cobradas nesse país de tantos déficits.

\section{A teoria do reconhecimento na chave dos direitos}

Uma das principais análises surgidas na virada da década de 1980 para a de 1990, e essencial para a teoria crítica, foi a questão do reconhecimento nas suas várias dimensóes. Os trabalhos seminais de Charles Taylor e Axel Honneth são exemplos desse processo. Tanto o texto de Taylor "A política do reconhecimento" quanto a Luta por reconhecimento de Honneth trazem elementos fundamentais que contribuem para o entendimento dos movimentos sociais no mundo contemporâneo. $\mathrm{O}$ ponto em comum entre ambos os autores é que enfatizam que o não reconhecimento produz formas de opressão, distorçóes reais, e, consequentemente, danos àqueles que são submetidos às diversas formas de desrespeito. Recuperam de Hegel sua análise acerca da importância dos conflitos sociais como a dimensão fundamental para a construção do reconhecimemto de grupos sociais, no processo de formação da eticidade da sociedade moderna: de que modo esses conflitos se desenvolvem nas relaçóes intersubjetivas para a construção do acordo social e como são importantes na construção das bases para a problematização dos conflitos sociais contemporâneos. Dão ênfase, ainda, 
à concepção dialógica das relações sociais dos invivíduos nas sociedades modernas, quando a base axiológica se funda sobre "indivíduos de igual dignidade", como Taylor (1994) define a passagem do princípio basilar do privilégio para o de direito nas sociedades ocidentais. Sai a honra e entra a dignidade dos indivíduos, indivíduos estes portadores de direitos humanos, como prescritos formalmente nas primeiras constituiçóes a falarem dos direitos dos cidadãos.

Na passagem da honra para os direitos, Taylor (1994) dá ainda especial atenção à potencialidade embutida na ideia de igual dignidade. Ao recusar a ideia do reconhecimento roussauniano de uma completa reciprocidade que se consubstanciaria na vontade geral da sociedade, Taylor equaciona a igual dignidade com o direito à diferença e recusa qualquer hipótese de homogeneidade nas sociedade ocidentais modernas. Analisando o Canadá, ele defende que o valor de igual dignidade seja alargado para grupos culturais diversos. Este seria o verdadeiro "multiculturalismo", quando grupos com culturas, histórias, religiôes e hábitos distintos possam conviver em paridade para preservar sua autenticidade na realização da igual dignidade. É a radicalidade da questão da diversidade, não mais vista como condescendência de um estrato superior, mas sim do reconhecimento do outro nas suas características diferenciadas. Assim sendo, a chave analítica de Taylor - autenticidade, a necessidade de reconhecimento do igual valor e respeito à diferença - passa a ser importante subsídio para a teoria crítica e para a análise dos movimentos sociais contemporâneos.

Dessa forma, tanto o reconhecimento social quanto o político tornam-se categorias essenciais para a construção da teoria crítica, que vai ser desenvolvida em várias formulaçóes teóricas e que apontam as diversas formas de desigualdades no mundo contemporâneo como eixos centrais de análise. Desigualdades que não se situam apenas na chave da classe, como bem demonstraram os movimentos feminista ou o dos Direitos Civis americano, que têm em comum a denúncia do não reconhecimento desses grupos como sujeitos de direitos, trazendo profundas consequências para a possibilidade de paridade de participação na esfera pública. E a necessidade do reconhecimento passa a guiar as formulaçóes de pensadores como Charles Taylor, Axel Honneth e Nancy Fraser, entre outros, que vão enfatizar os aspectos dialógicos das relaçóes sociais para que grupos sociais 
possam lutar pelo reconhecimento de sua dignidade e seu respeito para a conquista de direitos nos acordos sociais.

Tendo sempre como referência a questão da validade heurística destas análises para o contexto brasileiro, cabe lembrar que a promessa dos direitos modernos de liberdade e igualdade estiveram presentes também nas distintas versôes das constituiçôes brasileiras, mas o princípio da igual dignidade preconizado por Taylor não era a ideia-guia do nosso projeto republicano. Muito pelo contrário, nossa formação de nação, baseada que foi em constante exclusão de grupos desse acordo societário, e de forma dramática da população negra, se contentou com os registros formais do ideario de dignidade do indivíduo moderno e, mais do que as "ideais fora do lugar" de que fala Schwarz (1992), pode-se falar em "exclusividade de uso" dos princípios embutidos na noção moderna do indivíduo, pois a fruiçãa dos direitos civis e políticos era privilégio de grupo seleto (PAIVA, 2004, 2013; ALMEIDA; PAIVA, 2010). Por conseguinte, a formação social brasileira no que foram as "desigualdades duráveis", de que fala Tilly (1999), representa campo de estudo propício para a elaboração de uma teoria crítica, na qual a questão do reconhecimento, do respeito e suas formas análogas de desrespeito é central. Porque tampouco houve a passagem do acordo social com base na honra para o da igual dignidade, analisada por Taylor (1994): nosso acordo societário primou pela combinação desses ideais tão opostos para a reorientação das relaçóes sociais do mundo moderno. Mais do que a ruptura gradual de um mundo a outro, esses contrários se fundiram em uma síntese de valores ambíguos que orientou nossa modernidade excludente e desigual.

Isso posto, o objetivo da análise feita a seguir é mostrar como a teoria do reconhecimento, em especial através dos aportes trazidos por Nancy Fraser e Axel Honneth, trouxe importantes chaves analíticas para a compreensão dos movimentos sociais no mundo contemporâneo; como representam contribuiçôes fundamentais para a análise crítica dos movimentos sociais brasileiros; e também de que maneira cada um está referenciado a dimensôes analíticas diferenciadas e úteis na compreensão de movimentos sociais do Brasil. Para efeito de análise, será enfatizada a discussão dos dois autores em torno do reconhecimento e da redistribuição no sentido de mostrar os aportes de cada conceito, uma vez que a discussão empreendida por eles 
enriqueceu ainda mais a argumentação teórica desenvolvida por ambos. Deve-se concordar com Celi Pinto (2008), que defende a existência de uma falsa antítese entre Fraser e Honneth, pois suas análises se situam em momentos de elaboração teórica distintos. $\mathrm{O}$ pano de fundo será a análise do movimento negro, fortalecido pelas novas oportunidades políticas de que se falava acima acerca da redemocratização brasileira. Porque a redemocratização teve de lidar, e ainda lida, com todos os déficits no que concerne à fruição de direitos ao longo de nossa história republicana nas suas dimensôes legais, políticas e sociais. E uma das questôes centrais é o reconhecimento da legitimidade de demandas que pautam a esfera pública a denunciarem a incompletude da realização dos direitos mais básicos.

Quando Honneth escreveu Luta por Reconhecimento, enfatizou a concepção hegeliana da importância do reconhecimento intersubjetivo para a construção da identidade dos indivíduos, tanto na esfera afetiva relaçóes de afeto/amor - quanto na passagem para sua capacidade cognitiva - sua concepção de sociedade civil, afastando-se do estado da natureza - até a etapa seguinte, na esfera da universalização jurídica, que fecharia o "sistema de eticidade", palco das lutas por reconhecimento, formulado por Hegel. Honneth vai desenvolver essas esferas em um percurso teórico bastante original ao incluir a psicologia social de George H. Mead (1867), para chegar à sua terceira dimensão, da solidariedade social, o que implica que o sujeito apenas pode se auto-afirmar no meio social quando passa a fazer parte de uma comunidade jurídica. É o desenvolvimento do "Me" da auto-realização individual, que é construído com as convicçôes axiológicas da coletividade (HONNETH, 2003, p. 148).

E essa ampliação para o "outro generalizado" de que fala Mead (1967), vale dizer, a liberdade individual que se realiza no social para a construção da solidariedade social mais ampla, dá a Honneth o caminho para a construção de uma terceira esfera, a esfera da solidariedade. Lançando mão da tipologia de Marshall (1967) sobre a construção dos diretos humanos, Honneth enfatiza que cada nova fase de afirmação jurídica do Direito vai resultar em novas lutas de ser membro da comunidade de valores. Mas lembra que há várias formas de desrespeito quando o status de uma pessoa de direito fica apenas no plano formal. Como lembra Patrícia Mattos (2006, p. 87), Honneth pretende mostrar "[...] como os conflitos sociais 
são essencialmente com base em uma luta por reconhecimento social e que essa luta é o motor das mudanças sociais e, consequentemente, do processo de evolução da sociedade", sendo a dimensão emancipatória das lutas por reconhecimento o elemento central da teoria crítica.

São conhecidas as estruturas das relaçóes sociais de reconhecimento de Honneth. Seus modos de realização se dão nas esfera do amor/afeto, das relaçôes jurídicas e da comunidade de valores, três dimensôes importantes para a realização da simetria nas relações entre os indivíduos, simetria significando para Honneth (2003, p. 211) que "[...] todo sujeito recebe a chance, sem graduçôes coletivas, de experienciar a si mesmo, em suas próprias realizaçóes e capacidades, como valioso para a sociedade”. Esta será a possibilidade de realização da solidariedade social, isto é, quando há a consideração das diferenças e respeito para sua realização. Influenciado por Mead, Honneth analisa esse importante momento da saída da solidariedade entre os mais próximos (o que Mead chama de significant others) para a solidariedade para outros grupos sociais não conhecidos (generalized others), quando se dá o reconhecimento de ser membro da comunidade de valores e ser capaz de se atingir a paridade mínima necessária para fazer parte da comunidade política no usufruto real dos direitos humanos.

Mas são as formas de desrespeito formuladas por Honneth nas três esferas do afeto, dos direitos e da comunidade de valores que podem justificar o nexo entre desrespeito moral e luta social. Reagindo contra as análises sociológicas que predominaram desde a Escola de Chicago para a análise dos conflitos sociais, vale dizer, a questão do interesse e da distribuição desigual das oportunidades materiais, Honneth vai defender uma teoria que traga para a análise da luta social a questão dos "sentimentos morais de injustiça e não de interesses dados" (HONNETH, 2003, p. 256). Lembra ainda que as três estruturas das relaçóes sociais do reconhecimento não podem ser tratadas abstratamente, pois precisam de um conflito inscrito nas experiências para que se possa formar a base de um movimento coletivo. Mas o sentimento de injustiça que move um movimento social precisa ainda de outros elementos: livrar-se da violência material e simbólica quando sai do nível da neutralidade imposta pelos diversos padrôes de dominação; ter a consciência do que é a questão central de sua luta; e ter em mente a difícil equação entre ideias gerais e experiências pessoais. E é nesse ponto que 
Honneth vê a possibilidade de uma "ponte semântica" entre o desrespeito experimentado pelo indivíduo e a construção de identidades coletivas nos movimentos sociais (2003, p. 258):

Sentimentos de lesão dessa espécie só podem tornar-se a base motivacional de resistência coletiva quando o sujeito é capaz de articulá-los em um quadro de interpretação intersubjetivo que os comprova como típicos de um grupo inteiro; nesse sentido, o surgimento de movimentos sociais depende da existência de uma semântica coletiva que permite interpretar as experiências de desapontamento pessoal como algo que afeta não só o eu individual, mas também um círculo de muitos outros sujeitos.

Honneth fala aqui dos novos frames (quadros de interpretação intersubjetivos), da necessidade das redes de "muitos outros sujeitos". E se relacionarmos as formas de desrespeito analisadas por Honneth no que se refere ao ideal normativo dos direitos civis, políticos e sociais, vemos o quanto é importante para se entender o momento em que os indivíduos que sofrem as formas de desrespeito nas relaçôes primárias (para a construção de sua autoconfiança), nas relaçôes jurídicas (quando se logra o autorrespeito) e na comunidade de valores (para conquistar sua autoestima), e o que cada uma dessas dimensôes pode implicar lutas intersubjetivas, ajudam muito a entender o momento em que os indivíduos logram sair da ação paralisante das formas deformadas ou errôneas de relaçóes sociais. Sua pergunta de fundo é: "[...] como a experiência de desrespeito está ancorada nas vivências afetivas dos sujeitos humanos, de modo que possa dar, no plano motivacional, o impulso para a resistência social e para o conflito, mais precisamente para uma luta por reconhecimento?" (HONNETH, 2003, p. 214). Ressalte-se aqui a importância da experiência vivida para que tal impulso possa se realizar: a experiência ligada à consciência, que é traduzida em novos frames, são a base motivacional da resistência coletiva.

E é o processo de engajamento social que pode fazer com que os indivíduos recuperem algo da autoestimaperdida, fazendo com que seus participantes consigam alcançar "uma espécie de estima mútua" (HONNETH, 2003, p. 260) para a construção de redes de associação, que seriam os espaços contrapúblicos de Fraser. Trata-se de um processo de aprendizado social, no qual são elaborados novos quadros interpretativos para a exposição de determinado conflito, conflito este que busca a 
ampliação do reconhecimento na sua dimensão moral. Doug McAdam (1982), ao analisar o movimento dos direitos civis nos Estados Unidos, define como "liberação cognitiva" o momento em que se dá o engajamento dos atores em movimentos sociais, isto é, a construção do ator social em processo. Os frames são construídos enquanto o movimento se desenvolve e se consolida, o que, para os atores, resulta em um processo de aprendizado social emancipatório.

Tal processo de aprendizado social para a formação do quadro interpretativo necessita realizar duas das dimensóes de uma só vez: “[...] provocar uma diferenciação dos diversos padróes de reconhecimento e, ao mesmo tempo, dentro das esferas de interação assim criadas, liberar o respectivo potencial internamente inscrito" (HONNETH, 2003, p. 267). E é na segunda dimensão, aponta o autor, na diferenciação dos padrões de reconhecimento e na liberação do potencial interno do conflito, que está o impulso para as lutas sociais: quando o reconhecimento jurídico e a estima social são móveis para formas coletivas de resistência: “[...] preparado por semânticas subculturais em que se encontra para os sentimentos de injustiça uma linguagem comum, remetendo, por mais indiretamente que seja, às possibilidades de uma ampliação das relações de reconhecimento" (HONNETH, 2003, p. 267). E o que deve estar sempre presente na sua concepção é o ideal normativo em que valores possam ser o fio condutor das lutas sociais por direitos. Este é um ponto crucial para a contribuição de Honneth para os movimentos sociais, pois os processos construídos em relaçóes intersubjetivas logram alcançar a ampliaçáo do ideal normativo nas três dimensôes para a vida social; por isso, têm enorme validade heurística para se entender a emergência do movimento negro brasileiro.

Mas Honneth não deixou essa discussão em um plano ideal típico da comunidade de valores. A relação feita por ele entre as estruturas das relaçóes sociais do reconhecimento tem nas suas formas de desrespeito a chave do que é a não realização das formas de reconhecimento. Ao invés da aquisição da autoconfiança na dimensão do amor, têm-se os maus tratos e a violação; ao invés do autorrespeito conquistado pelo reconhecimento jurídico, há a privação de direitos e a exclusão; por último, no que concerne à autoestima compartilhada na comunidade de valores, encontram-se a degradação e a ofensa. Pode-se, então, defender 
que a violência ao indivíduo, a privação de direitos e a privação de status, respectivamente, representam dimensôes analíticas fundamentais para o entendimento dos níveis de desrespeito estrutural existentes nos acordos sociais. Trazendo a questáo para as relaçóes raciais no Brasil, pode-se constatar que o processo fraturado para a inclusão do negro na vida republicana significou a impossibilidade de aquisição da autoconfiança, o autorrespeito náo reconhecido no ordenamento jurídico, e a impossibilidade de se conquistar a estima junto à "comunidade de valores" excludente (HASENBALG; SILVA, 1992).

Uma das grandes distinçôes analíticas entre Honneth e Nancy Fraser reside no nível da análise da formação da identidade coletiva. Enquanto Honneth está preocupado em entender como se processa o possível engajamento em lutas sociais para que os indivíduos saiam das situaçóes paralisantes das formas de desrespeito construídas em acordos sociais injustos, Fraser traz seu foco analítico para a distinção entre as injustiças culturais e as socioeconômicas. Enquanto a primeira se concentra na luta por reconhecimento, as injustiças econômicas trazem o pêndulo para a redistribuição. É uma distinção que ajuda a entender, segundo a autora, a natureza das formas de injustiça nas lutas dos movimentos sociais contemporâneos, embora estejam sempre relacionadas.

Assim, quando Fraser se pergunta se há movimentos que estão mais na chave da "redistribuição ou reconhecimento", ela cria categorias analíticas que lhe vão possibilitar defender sua tese principal: "that of developing a critical theory of recognition, one that identifies and defends only those versions of cultural politics of difference that can be coherently combined with the social politics of equality" (FRASER, 1995, p. 80). Porque, para Fraser, somente ao integrar reconhecimento com redistribuição, pode-se entender os movimentos contemporâneos. Assim, partindo das duas formas de injustiça principais, a socioeconômica e a cultural, a autora problematiza o que está subjacente às demandas contemporâneas dos movimentos sociais. Seria demasiado simplista, portanto, relacionar redistribuição com recursos materiais e reconhecimento com recursos culturais, pois, para Fraser, o desafio está em criar ferramenta analítica que lhe permita resolver o dilema entre a má distribuição e o não reconhecimento, relação sempre presente em sua análise. Porque a má redistribuição impossibilita o reconhecimento 
de grupos subalternizados e o não reconhecimento resulta em distribuição material injusta.

Tentando ir além das análises de Taylor e Honneth, dentre outros, ela vai desenvolver o argumento de que não é possível compreender a questáo das injustiças socioeconômicas sem fazer uma distinção analítica entre estas com as injustiças no campo simbólico. É o que afirma: "Cultural norms that are unfairly biased against some are institutionalized in the state and the economy; meanwhile, economic disadvantage impedes equal participation in the making of culture, in public sphere and in everyday life" (FRASER, 1995 , p. 80) Essa distinção é crucial para que ela se pergunte: qual é a relação entre as demandas por reconhecimento, que visam às injustiças culturais e as demandas por redistribuição, que se remeten às injustiças socioeconômicas? E ainda: que tipo de interferência se dá quando ambas as demandas acontecem simultaneamente?

Fraser desenvolve uma argumentação sobre as lutas por redistribuição e reconhecimento baseando-se nos movimentos sociais contemporâneos, traçando uma tipologia, cujo objetivo é a busca por uma melhor interpretação heurística. Na ponta desse espectro conceitual, encontramse as demandas baseadas maiormente na redistribuição, ou seja, as lutas de classe que denunciam exploração nas relaçóes de trabalho; na outra ponta do mesmo espectro, estão as lutas de movimentos que se formaram reivindicando novos direitos com base em demandas por mudança dos padróes culturais (por exemplo, orientação sexual reafirmada), o que estaria essencialmente no âmbito do reconhecimento. Mas Fraser vai lembrar de dois movimentos poderosos no mundo contemporâneo - o feminista e o negro - cujas lutas demandam tanto redistribuição quanto reconhecimento, e eles estão imbricados. Porque o não reconhecimento histórico dos dois grupos realmente resultou em profundas injustiças econômicas e vice-versa, não apenas nos Estados Unidos, mas também em todas as sociedades ocidentais "modernas", cujo marco jurídico foi construído para os homens, os homens brancos, e os homens brancos com renda.

Em texto posterior, em seu debate com Honneth, Fraser (FRASER; HONNETH, 2003) enfatiza que se trata de uma distinção analítica para 
melhor compreender a predominância de demanda por redistribuição ou reconhecimento, e traz o conceito weberiano de status para mostrar que suas reflexóes conceituais de classe/status, economia/cultura e má distribuição/falta de reconhecimento devem estar inseridas na perspectiva histórica da organização social para entender que as injustiças de status são também injustiças econômicas, que questôes econômicas podem estar atreladas a posiçóes de prestígio construídas no ordenamento social, e que ambas podem trazer tanto o náo reconhecimento como a má distribuição. Vai lembrar que são distinçóes analíticas para que se possa ater à perspectiva crítica: "Rather, it must probe beneath appearances to reveal the hidden connections between distribution and recognition. It must make visible, and criticizable, both the cultural subtexts of nominally economic processes and the economic subtexts of nominally cultural practices" (FRASER; HONNETH, 2003 , p. 62). E no "perspectivismo dual" que elabora para considerar tanto os níveis cultural quanto econômico subjacentes às formas da desigualdade, Fraser, em última análise, quer poder avaliar as condições de justiça de qualquer prática social: a perspectiva do reconhecimento para verificar o que se consideram geralmente como políticas de redistribuiçáo econômica e a perspectiva da redistribuição para focalizar o que geralmente se considera como questôes de reconhecimento. Tal perspectiva lhe permite atentar para as condiçóes intersubjetivas de redistribuição e reconhecimento para que seja possível a paridade na participaçâo, seu foco principal.

Honneth, por sua vez, ao responder Fraser, rejeita a diferenciação entre "simbólico" e "material" e defende a tese de que a teoria crítica atual deve estar ancorada em uma teoria do reconhecimento, cujo marco de referência seja esta teoria analisada em distintos níveis para que possa ser estabelecido o elo entre as causas sociais de sentimentos generalizados de injustiça com os objetivos normativos de movimentos emancipatórios. Assim, ao se orientar por demandas normativas, a teoria crítica não pode se ater aos movimentos sociais existentes, como critica em Nancy Fraser. Ao propor uma "fenomenologia das experiências de injustiça social", quer ir além dos movimentos já organizados e dá um passo atrás na sua dimensão analítica, com o intuito de ver as formas ainda não articuladas do descontentamento social e sofrimento. Defende, portanto, que sejam consideradas as expectativas normativas dos sujeitos, vale mencionar, ver de que modo a questão da 
violação das expectativas postas e asseguradas na sociedade como um todo não contemplam grupos específicos. Assim, a análise deve ter como ponto central o fundo normativo para todos os grupos sociais: "If the adjective 'social' is to mean anything more than 'typically found in society', social suffering and discontent possess a normative core" (FRASER; HONNETH, 2003, p. 129).

Ainda na sua resposta a Fraser, Honneth tem a oportunidade de diferenciar as três esferas de reconhecimento - amor, sistema legal e realização nas sociedades capitalistas, ressalta que esta última, a realizaçáo, foi construída de forma ideológica desde sua base e que grande parte dos grupos sociais não são reconhecidos como tendo esse tipo de realização, uma vez que não dispóem dos mesmos recursos materiais. Mas sua aposta é que este é um ideal normativo revolucionário e que levou a duas esferas completamente distintas: a) o indivíduo passou a ter a possibilidade de ser respeitado como igual a todos os outros membros da sociedade; b) ao mesmo tempo a estima social do indivíduo depende de uma escala hierárquica de valores. Por isso, entre a nova hierarquia de status para atingir tal estima social e a distribuição desigual dos recursos materiais, os indivíduos têm com o ideário de direitos na esfera legal, e a autoestima a ser conquistada na esfera da realização na comunidade de valores, a dimensão normativa para que tal percurso possa ser realizado.

Não é por outra razão que Honneth, ao discordar de Fraser, defende a importância de se considerar os valores culturais na constituição da esfera econômica e que as formas de desrespeito são as bases de todos os conflitos sociais. E a gramática moral dos conflitos que giram em torno de questóes de políticas de identidade em estados democráticos é determinada pelo reconhecimento do princípio da igualdade legal, sendo expressóes da expansão da luta pelo reconhecimento legal, centro da ética política. $\mathrm{Na}$ sua teoria da justiça, os três princípios do reconhecimento - o pessoal, o legal e o social - têm de estar contemplados para a realizaçáo da constituição moral da sociedade.

\section{Teorias do reconhecimento e o contexto brasileiro}

Não há como não pensar no caso brasileiro a partir do que foi analisado: há um histórico de formas de desrespeito no plano jurídico e o 
não reconhecimento na comunidade de valores no processo da formação sociopolítica brasileira. Não há a construção da comunidade de valores da qual falam Taylor e Honneth, pois não são dadas as condiçóes para o alcance da paridade mínima necessária para o reconheciento intersubjetivo de grupos diferenciados na esfera pública. A construção social da cidadania brasileira sempre foi excludente, precisando de adjetivos para sua definição - "regulada", "subcidadania", "passiva”, "da dádiva”, como vários autores já analisaram - em um processo em que alguns poucos grupos têm o reconhecimento do igual valor, que sempre guardou grande afinidade com o processo de modernização então construído, também necessitado de adjetivos - "excludente", "conservador", "autoritário", "patrimonialista”. 5

$\mathrm{O}$ ideario dos direitos estava posto formalmente e as instituiçóes republicanas que foram estabelecidas eram norteadas pela ideia dos direitos humanos com seus "significantes vazios" (LACLAU, 2000), vale citar, não remetiam a significados fortes que pudessem trazer mudanças. No plano formal, estavam lá, prescrevendo igualdade e liberdade para todos; entretanto, para o impedimento de que a efetivação dos direitos resultasse em móvel de explicitação de conflitos, foram criados mecanismos poderosos que permitiram que o modelo republicano se referisse a grupos determinados enquanto outros eram mantidos em reconhecimento errôneo, tamanha a eficácia da desigualdade naturalizada. E tamanho é o nível de desigualdade que as consequências do desrespeito, como lembra Emil Sobottka (2015), estáo tanto no nível individual, ou seja, na dificuldade linguística de expressar a consciência de injustiça, quanto no nível social, nas formas da organização social brasileira que não aportam instâncias para que as experiências cotidianas de injustiça possam ser compartilhadas em um nível eticamente construído. Esta dificuldade linguística apontada pelo autor está intrinsicamente relacionada com os indicadores vergonhosos da educaçáo brasileira, aspecto fundamental para tudo o que está se discutindo aqui e uma das bases para todos os nossos déficits.

5 Devido ao escopo do presente artigo, não cabe se estender em tal análise. Há excelentes interpretações no pensamento social brasileiro que contemplam o papel do Estado para regular a cidadania (CARVALHO, I99 I; SANTOS, 1979), a desigualdade naturalizada, cujo resultado foi a subcidadania (SOUZA, 2003) e ainda as relações sociais paternalistas (SALES, 1994) e um estado autoritário (VIANNA, 1997), conservador (REIS, 1998) e neopatrimonialista (SCHWARTZMAN, 1988). Ver Silva, 2010, para uma análise crítica do periodo. 
Mas cabe perguntar quais foram os fatores que resultaram na equação das mais perversas para a validação de um acordo normativo que resultou ser excludente para vários grupos sociais, ressaltando o legado de séculos de uma ordem escravocrata? a) uma hierarquia consolidada nas relaçóes sociais de mandonismo e clientelismo; b) um paternalismo nas relaçóes sociais que mitigava e deformava tais relações, com um padrão de subserviência e de cordialidade, indispensáveis para a sobrevivência social daqueles que não tinham o mínimo de autonomia; c) a organicidade nessas relaçóes, cega às desigualdades raciais e sociais, em que cada um sabia seu lugar. E o Estado que era então construído se encaixava como uma luva para manter o autoritarismo, o conservadorismo e o personalismo que manteve a exclusão da maioria da população, em especial a negra (SCHWARTZMAN, 1988). A reforçar ainda todas essas marcas, havia ainda a Igreja Católica pré-conciliar que, em uma chave de afinidade eletiva conservadora pregava a obediência aos detentores do poder e o conformismo diante de ordem tão desigual. Foi a construção de uma república distante dos cidadãos, como analisou José Murilo de Carvalho (1991), pois o povo não se reconhecia na República que se formava.

E o nascimento da república brasileira coincidiu com um momento perverso da história do Brasil: com a Abolição ocorrida no ano anterior, não houve nenhuma política pública para a integração dos libertos no projeto republicano que se formava. Muito pelo contrário, os negros foram deixados à sua própria sorte, ocupando espaços precários e subalternos de uma sociedade que começava a se urbanizar com mais força, pois não tiveram acesso universalizado à escola, e, por conseguinte, não tinham direito ao voto. No marco referido acima, foi o não reconhecimento do ex-escravo como indivíduo que deveria ser integrado no projeto de nação em formação. Permanecia assim o valor de não pessoa que lhe fora conferido no longo período de escravidão no Brasil. Nesse caso, não houve a passagem da honra para a dignidade no sentido dado por Taylor (1994): houve a preservação do acordo social dos grupos seletos que detinham o poder, em um jogo de ambivalências, como foi descrito, e que apresentava um quadro difícil de ser decodificado por aqueles que se situavam às margens do projeto republicano. $\mathrm{O}$ conflito era mitigado pelos fatores mencionados, cuja eficácia levou as próprias vítimas a assumirem a culpa por não 
"merecerem" o reconhecimento de seu igual valor. Em síntese: a culpa era das vítimas. E esse é momento que Honneth lembra acerca dos mecanismos poderosos dos grupos dominantes que impedem o reconhecimento de grupos não reconhecidos para que a mudança social seja iniciada. Sem o ideal normativo de justiça social que implica a distribuição mínima dos direitos para uma vida boa na sociedade mais ampla, as desigualdades estruturais ficam assim naturalizadas.

Para a população negra, a sociedade hierárquica, paternalista e autoritária trouxe mecanismos que mantinham o controle de um acordo social cujas relaçóes eram exaltadas como cordiais e harmoniosas, em um cenário ainda mais efetivo durante a Era Vargas, com o cultivo da ideia de uma só raça do "povo" brasileiro, que deixou marca indelével para o fortalecimento da ideologia da democracia racial por várias décadas. As mobilizaçóes da população negra eram incipientes, uma vez que várias pessoas de cor (quanto mais claras, melhor) conseguiram adquirir um status para se integrar na sociedade de classes, o que alimentava ainda mais a ideia da democracia racial (GUIMARÁES, 2002). O surgimento do conflito em torno da questão racial, cuja desigualdade era denunciada por militantes como Abdias do Nascimento (2009) no Pós-Guerra e por estudos acadêmicos iniciados por Florestan Fernandes (1978) na década de 1950, teve de ser adiado em 1964, com o golpe militar, que novamente reforçou a ocultação da questão racial brasileira, inclusive retirando a classificação racial do Censo realizado em 1970.

Não foi por outra razão que se iniciou a presente análise relacionando a importante interseçấo entre o surgimento dos movimentos sociais no final da década de 1970 e o marco dos direitos humanos como novos reguladores de organizaçóes coletivas que pediam mudança social, juntamente com a base analítica da teoria crítica defendida por Fraser e Honneth. Há que se concordar com Honneth de que o ideal normativo para as lutas deve estar sempre presente. A ação do MNU na década de 1980 trouxe várias pautas que envolvem a luta por reconhecimento de suas demandas na busca por maior justiça social e reconhecimento cultural, revelando: a) primeiramente, que a desigualdade brasileira náo era apenas social e que foi possível a construçáo de um novo marco interpretativo que denunciava justamente a democracia racial; b) como segunda pauta importante, que a 
população negra (pretos e pardos) não tinha acesso aos direitos mais básicos como o direito civil de acesso à justiça e os direitos sociais de educação e de saúde; c) que havia ainda a necessidade de se mudar o marco legal que naturalizava o desrespeito às pessoas de cor, e os movimentos negros trabalharam junto aos quadros políticos que se formaram com a redemocratização para que o novo marco legal fosse construído com a Carta de 1988, contemplando a defesa de direitos não reconhecidos no acordo social, tais como a injúria e a ofensa raciais.

Foram formas de reconhecimento fruto do que Honneth chamou de aprendizado social, cujos conflitos surgiram em forma de movimentos sociais ao longo da década de 1980 . Foi o momento em que formas de invisibilização racial se traduziram na denúncia contra as mais variadas formas de desrespeito (GONZALEZ; HASENBALG, 1982). E foi nesse processo intersubjetivo de que fala Honneth, quando o reconhecimento das três formas de desrespeito contra a população negra pode ser realizada de forma coletiva no engajamento na luta social, é que o movimento social ganhou força. ${ }^{6}$

\section{Considerações finais}

Para finalizar, e para exemplificar como esse processo de um movimento social sustentado se transformou em arenas de luta por reconhecimento, cabe ressaltar duas demandas do movimento negro: a) a primeira foi o reconhecimento da importância cultural da população negra do país, demanda do movimento negro, com a reformulação curricular de 2003, com a promulgação da Lei no 10.639 , que prescreveu a inclusão no currículo oficial do Ensino da História e Cultura Afro-Brasileira; b) a segunda foi a demanda por maior distribuição de bens materiais, quando se privilegiou a demanda por ação afirmativa nas universidades públicas brasileiras (ALBERTI; PEREIRA, 2007) no momento de preparação para a participação brasileira na Conferência de Durbam contra o

6 Não se está defendendo aqui políticas de identidade essencializadas, mas sim que a identidade negra foi importante como estratégia para a denúncia da desigualdade racial. Seguindo com Honneth e Fraser, o movimento negro trouxe questões para a esfera pública não antes contempladas, com a demanda tanto pelo reconhecimento cultural (nas dimensões sociais e simbólicas), quanto pela redistribuição econômica, em especial no acesso à educação. Ver Pereira (2008), para uma excelente análise do movimento negro brasileiro. 
Racismo, realizada em 2001. A ideia de ação afirmativa no ensino superior representou um processo tenso de se questionar a neutralidade da seleção do ingresso pelo vestibular, como ressaltou Joaquim Barbosa (2001), uma vez que se questionavam valores enraizados na nossa ideia de justiça social baseada no mérito.

E a década de 2000 foi palco de grandes transformaçóes nas universidades públicas brasileiras. Estas passaram por intenso processo de avaliação de seus marcos normativos e várias políticas de ação afirmativa foram concebidas e implantadas entre 2002 e 2011 a partir de decisóes tomadas pelos próprios conselhos universitários (com a exceção de algumas poucas universidades estaduais); significou processo tenso de construção de novos padróes de justiça social no ensino superior, com o reconhecimento da necessidade de se mudar a cor e a classe nas universidades públicas brasileiras. Hoje, tais políticas são reconhecidas como necessárias, ainda que tenha prevalecido, na grande maioria das universidades, a inclusão pela ação afirmativa focada nas escolas públicas de ensino médio e não na população negra, e embora essa demanda tenha sido sempre reivindicada pelo movimento negro. Esse fato demonstra a dificuldade da sociedade brasileira em lidar com as desigualdades raciais. De qualquer modo, foi um momento exemplar no sentido dado ao longo do texto acerca da importância da construção de frames por atores que veem a importância de se questionar formas de injustiça, no caso em tela, a injustiça do acesso ao ensino superior; de fazerem escolhas estratégicas, como a denúncia da desigualdade racial nas universidades públicas. Desde os dados publicados pelo IPEA, em 1999, (HENRIQUES, 2001), abriram-se espaços discursivos sobre a cor do ensino superior nas universidades públicas e argumentos foram construídos na luta pelo reconhecimento da desigualdade racial e não apenas social. ${ }^{7}$

O processo de adoção de ação afirmativa nas universidades públicas foi ainda exemplar para a formulação da Lei de Cotas de 2012, quando

7 Há inúmeras análises sobre o processo de implantação de cotas e outras modalidades de ação afirmativa nas universidades públicas. Tive a oportunidade de acompanhar esse processo e de realizar uma das poucas pesquisas qualitativas sobre a questão. Foram realizadas em duas etapas, de 2005 a 2008 e de 208 a 20 III, quando foram visitadas 24 universidades públicas de todas as regiões do país. Ver os resultados em Paiva, 2013. Almeida e Paiva, 2012. 
as universidades federais tiveram de aplicar programas de cotas para negros, indígenas, estudantes de escolas públicas e pessoas com deficiência, resguardando a composição étnico-racial de cada estado da federação. Foi assim o reconhecimento da necessidade de maior justiça social no acesso à educação superior, agora com a política pública de inclusão em todas as universidades federais. Foi também o reconhecimento do processo desencadeado pelas universidades públicas entre 2002 e 2011, quando mais de $70 \%$ das universidades públicas federais e estaduais pensaram em algum programa de ação afirmativa (RIBEIRO, 2017).

$\mathrm{O}$ ano de 2012 trouxe ainda o reconhecimento, por parte do Supremo Tribunal Federal, da constitucionalidade da cota para negros adotada pela Universidade de Brasília. Quando se analisam as sentenças proferidas pelos juízes para tal ação, pode-se verificar como os frames construídos pelo movimento negro ao longo da década anterior tinham sido aceitos pelos 11 juízes: em decisão unânime, proferiram sentenças baseadas em maior justiça no que concerne à raça no ensino superior, na necessidade de maior diversidade nos campi das universidades públicas brasileiras e ainda na importância de se estarem remediando injustiças históricas e estruturais sofridas pela populaçáo afrodescendente.

$\mathrm{Na}$ chave analítica de Fraser, o movimento negro mostra como as chaves de redistribuição e reconhecimento estão profundamente relacionadas para demandas de mudança social: o reconhecimento da justiça de se promoverem políticas que levem à maior paridade para participação na esfera pública por meio do acesso ao ensino superior tem como consequência a redistribuição de recursos materiais. $\mathrm{Na}$ chave de Honneth, cabe ressaltar a importância da ação do movimento negro para a socialização moral dos sujeitos e, em um segundo passo, para a integração moral na sociedade. É um longo processo de aprendizado social não só para os militantes do movimento mas também para o reconhecimento da questáo racial na esfera pública brasileira mais ampla.

\section{Referências}

ALBERTI, V; PEREIRA, A. (Org.). Histórias do movimento negro no Brasil. Rio de Janeiro: FGV; Pallas, 2007. 
ALMEIDA, L. C.; PAIVA, A. R. Mudança no campus: falam os gestores das universidades com ação afirmativa. In: PAIVA A. R. (Org.). Entre dados e fatos: ação afirmativa nas universidades públicas brasileiras. Rio de Janeiro: PUC-Rio: Pallas, 2010. p. 75-115.

ARENDT, H. A condiçáo humana. Rio de Janeiro: Forense Universitária, 1993.

BARBOSA, J. Açáo afirmativa e princípio constitucional da igualdade. Rio de Janeiro: Renovar, 2001.

BENDIX, 1969.

CALHOUN, C. Social Theory and the Politics of Identity. In: CALHOUN, C. (Org.) Social Theory and the Politics of Identity. Massachussetts: Blackwell, 1994.

CARVALHO, J. M. Os Bestializados. São Paulo: Cia. Das Letras, 1991.

CASTEL, R. As metamorfoses da questão social. Petrópolis: Vozes, 1998.

DAGNINO, E. Os movimentos sociais e a emergência de uma nova cidadania. In: DAGNINO, E. (Org.). Anos 90: Política e sociedade no Brasil. São Paulo: Editora Brasiliense, 1994.

DURHAM, E. Movimentos Sociais: a construção da cidadania. Novos Estudos Cebrap, n. 10, p. 24-30, out.1984.

FERNANDES, F. A integraçáo do negro na sociedade de classes. São Paulo: Editora Ática, 1978.

FRASER, N. Rethinking the Public Sphere: A Contribution to the Critique of Actually Existing Democracy. Social Text, n. 25/26, p. 56-80, 1990.

FRASER, N. From Redistribution to Recognition? Dilemmas of Justice in a "Postsocialist Age". New Left Review, v. 212, p. 68-93, 1995.

FRASER, N.; HONNETH, A Redistribution or recognition? A political- philosophical exchange. New York: Verso, 2003.

GOHN, M. da G. Movimentos sociais e redes de mobilizaçáo no Brasil contemporâneo. Petrópolis: Vozes, 2010.

GONZALEZ, L.; HASENBALG, C. A. Lugar de negro. Rio de Janeiro: Marco Zero, 1982.

GUIMARÁES, A. S. Classes, raças e democracia. São Paulo: Editora 34, 2002.

HABERMAS, J. Mudança estrutural na esfera pública. Rio de Janeiro: Tempo Brasileiro, 1984.

HASENBALG, C.; SILVA, N. do V. Relaçóes raciais no Brasil Contemporâneo. Rio de Janeiro: Rio Fundo, 1992.

HENRIQUES, R. Raça e gênero nos sistemas de ensino. Brasília: Unesco, 2001.

HOLSTON, J. Cidadania insurgente - Disjunçôes da democracia e da modernidade no Brasil. São Paulo: Companhia das Letras, 2013. 
HONNETH, A. A luta por reconhecimento. São Paulo: Editora 34, 2003.

LACLAU, Ernesto. Identity and Hegemony. The Role of Universality in the Constitution of Political Logics. In: Butler, Laclau and Zizek, Contigency, Hegemony, Universality. London: Verso, 2000.

MARSHALL, T. H. Cidadania, classe social e status. Rio de Janeiro: Zahar, 1967.

MATTOS, P. A sociologia política do reconhecimento. São Paulo: AnnaBlume, 2006.

MCADAM, D. Political Process and the Development of Black Insurgency. Chicago: The University of Chicago Press, 1999.

MEAD, G. H. Mind, self and society. Chicago: University of Chicago Press, 1964.

MELUCCI, A. A invençáo do presente. Petrópolis: Vozes, 2001.

NASCIMENTO, A. Quilombismo. Afrocentricidade: uma abordagem epistemológica inovadora. Vol. 4. São Paulo: Sumus, 2009.

PAIVA, A. R. A difícil equação entre modernidade e desigualdade. Intersecçóes, v. 6, p. 7-17, jul. 2004.

PAIVA, A. R. Políticas públicas, mudanças e desafios no acesso ao ensino superior. In: PAIVA, A. R. (Org.). Açáo afirmativa em questáo: Brasil, Estados Unidos, África do Sul e França. Rio de Janeiro: Pallas Ed., 2013.

PEREIRA, A. M. Trajetórias e perspectivas do movimento negro brasileiro. Belo Horizonte: Nandyala, 2008.

PINTO, C. R. Notas sobre a controvérsia Fraser-Honneth informada pelo cenário brasileiro. Lua Nova, v. 74, p. 35-58, 2008.

REIS, E. P. Processos e escolhas. Rio de Janeiro: Contra Capa, 1998.

RIBEIRO, M. Políticas de promoçáo da Igualdade Racial no Brasil. Rio de Janeiro: Garamond, 2014.

SALES, T. Raízes da desigualdade social na cultura política brasileira. RBCS, v. 9, n. 25, p. 26-37, 1994.

SANTOS, W. G. Cidadania e justiça. A política social na ordem brasileira. Rio de Janeiro: Campus, 1979.

SCHWARTZMAN, S. Bases do autoritarismo brasileiro. Rio de Janeiro: Ed. Campus, 1988.

SCHWARZ, R. As idéias fora do lugar. In: SCHWARZ, R. Ao vencedor as batatas. São Paulo: Livraria Duas Cidades, 1992. p. 11-31.

SILVA, J. P. Nota crítica sobre cidadania no Brasil. Idéias, v. 1, p. 195-119, 2010. Disponível em: https:// periodicos.sbu.unicamp.br/ojs/index.php/ideias/article/view/8649307. Acesso em: 10 nov. 2018. 
SOBOTTKA, E. Desrespeito e luta por reconhecimento. Civitas, v. 15, n. 4, p. 686-702, 2015.

SOUZA, Jessé. A construção social da subcidadania. BH:UFMG, 2003.

TARROW, S. Power in Movement. New York: Cambridge University Press, 1998.

TAYLOR, C. The Politics of Recognition. In: GUTMANN, A. (Ed.) Multi-culturalism. Princeton: The Princeton University Press, 1994. p. 25-73.

TELLES, V. S. Sociedade civil e a construção de espaços públicos. In: DAGNINO, E. (Org.). Anos 90: Política e sociedade no Brasil. São Paulo: Ed. Brasiliense, 1994. p. 91-115.

TILLY, C. Durable Inequalities. Berkeley: University of Califórnia Press, 1999.

TOURAINE, A. Pensar outramente. Petrópolis: Vozes, 2007.

VIANNA, L. W. A revoluçáo passiva. Rio de Janeiro: Revan, 1997.

\section{Theories of recognition and their heuristic validity for the analysis of citizenship and social movements in Brazil}

\section{Abstract}

The article will bring three theories developed by scholars in the "North" since the 1950s: on citizenship, on social movements and on Fraser's and Honneth's theory of recognition, in order to verify their heuristic validity in understanding contemporary social issues in Brasil. It will be shown that they are of great importance to analyse Brazilian public sphere since the redemocratization of the country. From a historical sociology it will be pointed out the changes that have been taking place in the normative arrangements in what concerns not only the emergence of social movements, but also the questioning of the persistent inequalities on race relations. It will be claimed that the concept of human rights is a powerful tool to achieve a new citizenship and that the theory of recognition represents an important conceptual frame of analysis for the understanding new social movements.

Keywords: Citizenship. Inequality. Forms of Recognition. Black Movement.

Recebido em 30/09/2018

Aprovado em 27/11/2018 